\title{
Poverty and world health: challenges and opportunities
}

The hard won health gains of the past half century have seemed to be under threat in many parts of the world during recent years. Gaps in health betweeen rich and poor have widened both between and within many countries. ${ }^{1}$ Despite unprecedented wealth creation in the past two decades, the number of people in absolute poverty, with incomes of less than $\$ 1$ per day, is growing and stands at around 1.3 billion. ${ }^{2}$ The international debt crisis, which currently affects predominantly sub-Saharan Africa has resulted, for example, in Mozambique spending $33 \%$ of its annual public expenditure on debt repayments, compared with $3.3 \%$ on health. ${ }^{3}$ Structural adjustment policies have resulted in reduced expenditure on health, education and welfare in many countries. ${ }^{4}$ Increasing gaps in health between rich and poor have also occurred in a number of industrialised nations including the USA, the UK and countries of eastern Europe. ${ }^{5-7}$ There is a resurgence of malaria and tuberculosis internationally, ${ }^{89}$ with poverty and breakdown of public health infrastructure contributing to their spread.

The latest World Development Indicators report demonstrates how, far from benefiting from entry into the global economy, large numbers of people have suffered as a consequence. For example, in the transitional economies of eastern Europe and central Asia the numbers of people living on less than $\$ 4$ a day have increased from 14 million in 1990 to 147 million by mid-1998, amounting to one person in three. ${ }^{10}$ In Indonesia the combination of sharp economic decline and political turmoil have resulted in an increase in the number of people living on less than $\$ 1$ a day from 22 million to $80-100$ million.

A number of factors are now combining to give rise to cautious optimism that the gravity of the situation is being recognised and that appropriate changes in policy may follow. Although the link between absolute poverty and ill health has long been known, a growing body of research health has long been known, a growing body of research has demonstrated the consistent association between relaindustrialised nations, including the US and the UK. ${ }^{5}$

The Organization of Economic Cooperation and Development, representing the most economically powerful industrialised countries, has set ambitious targets for a new development strategy including substantial reductions in mortality rates for children under 5 and maternal mortality by $2015 .{ }^{11}$ The excesses of economic restructuring policies and their adverse effects on health have been publicly acknowleged by a senior World Bank official, ${ }^{12}$ and its president, James Wolfensohn has stated "our primary goal in development must be to reduce the disparities across and within countries" ${ }^{13}$ Gordon Brown, the UK Chancellor has announced that he expects the IMF to agree on lor has announced that he expects the IMF to agree on
substantial sales of its gold reserves for debt relief for the poorest countries. ${ }^{14}$

Dr Gro Harlem Brundtland, the Director General of WHO, has indicated that she intends to make the reduction of gaps in health between rich and poor a key goal for her period in office ${ }^{15}$ WHO has set up the International Poverty and Health Network to promote the involvement of health and Health Network to promote the involvement of health professionals worldwide in actions to reduce poverty and its impacts on health. Her call to action deserves support and there are a number of ways in which health professionals can individuals. They can, for example, act as advocates for deprived populations lacking access to effective health care. This role could include lobbying governments and international bodies for increased resources for health and education. The British Medical Association has, for example, supported debt relief for the poorest countries and this need to be combined with sound policies for more equitable development, and an end to the imposition of policies such as user fees, which discourage the poorest from using services. Access to health care is also a problem in some rich countries and the American College of Physicians has lobbied for universal access to health care in the USA where over 40 million people currently lack access. ${ }^{16}$

Health professionals can assist in analysing and disseminating evidence about effective interventions to reduce the impact of poverty on health, building on the success achieved by the Cochrane Collaboration in providing rigorous systematic reviews of research findings for the development of clinical policies. ${ }^{17}$ Efforts are now needed to provide the evidence base for the organisation, management and delivery of health services that reduce inequalities in health and for policies to promote health through actions in other sectors such as education, social policy, agriculture, housing and finance. A new agenda for health services and public health research needs to be developed in conjunction with policy makers who must use the results. In the UK, the Medical Research Council has made health inequalities and the evaluation of interventions to reduce them priority areas in a recent call for bids for public health research.

Better documentation of the role that ill health plays in deepening poverty is also needed.A recent study in Bangladesh, for example, has demonstrated how the ill health of wage earners can cause families to sink into debt. ${ }^{18}$

There is a need to develop better monitoring systems for trends in health and access both to health care and the essential prerequisites for health (for example, clean water, sanitation, food and shelter) so that progress towards agreed targets can be examined and disseminated. This will increase the incentives for governments and funding institutions to implement the necessary policy changes. Existing disease surveillance systems should be strengthened so that bette data are available on trends in key diseases. This will require augmenting the epidemiological and public health capacity in many of the less developed nations. Greater investment in distance learning approaches such as internet based courses developed jointly by institutions in the North and South could help to meet some of the potential demand.

With cutbacks in aid from industrialised nations, more emphasis on international technical cooperation between health professionals is appropriate, provided that it is directed towards the needs of the poorest and does not inadvertantly exacerbate gaps between rich and poor. A number of countries or regions within them have impressive health statistics despite low per capita incomes and much can learnt by both less developed and industrialised countries from their health and social policies, examples include China, Sri Lanka, and Costa Rica. ${ }^{19}$

Poverty alleviation needs to be placed within the contex of sustainable public health ${ }^{19}$ in which the conditions necessary for the attainment and maintenance of health in the long term are defined. Currently, development strategies are generally focused on economic growth without taking into sufficient account the environmental impacts or the effects on health, inequity and social cohesion. Two overriding issue will need to be tackled - population growth in the less developed countries and unsustainable patterns of resource use by industrialised countries, leading to problems such as climate change. ${ }^{20}$ The first is closely associated with poverty through a range of mechanisms, including lack of education 
of women ${ }^{18}$ and the second requires both a re-appraisal of current resource intensive patterns of economic development and the exploitation of new technologies, for example for energy efficiency and renewable energy. ${ }^{21}$ These issues are clearly broader than the scope of the health sector but health professionals can help to ensure that better health is seen as a principal outcome by which initiatives to promote sustainable development can be assessed.

The UN Declaration of Human Rights ${ }^{22}$ mentions access to basic necessities of life, such as food and water as a universal human right and also includes access to health care, however more than 50 years after it was written we are still far from that goal. Without determined action now that objective will remain elusive.

ANDREW HAINES

Royal Free and University College Medical School, London

\section{Addendum}

Since this editorial was written the Cologne G8 Summit agreed that there would be a $\$ 70$ billion reduction in total debts of the poorest countries on top of $\$ 30$ billion already scheduled for cancellation under existing schemes. The qualification period for debt relief has been reduced from six to three years but subject to harsher IMF conditions. The debt relief will be funded by the sale of 10 million ounces of IMF gold stocks. While this is a substantial step forward much remains to be done because many countries will not see their annual payments cut appreciably and will not see their annual payments cut appreciably and
other heavily indebted countries are not covered by the agreement. (Jubilee 2000 UK personal communication.)
1 World Health Organization. Health for all in the twenty-first century. Geneva: 2 World Bank Poyerty reduction and the World Bank: progress and challenge in the 1990s. Washington, DC: World Bank, 1996 ees, 1960 and $1986 . N$

Whitehead M, Drever F. Health Inequalities: main findings and implications
for the future. In: Drever F, Whitehead M, eds. Health inequalities, decennial supplement no 15. Office for National Statistics. London: The Stationary Whitehead $M$, Dider

in health. In: Drever F, Whitehead M eds. Health ine on social inequalities F, Whitehead M, eds. Health inequalities, decennial supplement n-69. Office for National Statistics. London: The Stationary Office, 6 World Healt 0

Wealth O Organization. The World Health Report 1998. Geneva: World Weiss K, Addington W. Tuberculosis poverty's penalty. Am $¥$ Respir Crit Car

Christian Aid. One every second. London: Christian Aid, 1997.
Ekwempu CC, Maine D, Olorukoba MB, et al. Structural adjustment and health in Africa. Lancet 1990,336:56-7. W Whington: World Bank, 1999. 11 Organization for Economic Cooperation and Development. Shaping the 21 century: The contribution of development cooperation. Paris: OECD, 1996. wrong. The Debt Update 2 Mar 1998;
World Bank. World

World Bank. World development indicators 1998. Washington: World Bank, 14 Brummer A. Brown spurs G7 to debt relief. Guardian 27 Apr 1999;21.

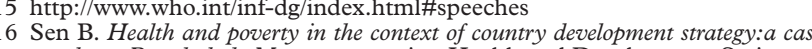
study on Bangladesh. Macroeconomics, Health and Development Series, n 26. Geneva: World Health Organization, 1997. WHO/ICO/MESD 26 18 World Bank. World Development Report: investing in health.Oxford:Oxford University Press, 1953. Mc Cally M, Haines A, Fein O, et al. Poverty and ill health: physicians ca McMichael AJ, Haines A, Kovats S, et al. Climate change and human healt Geneva: World Health Organization, 1996. EHG 96/7 von Weiszacker E, Lovins A, Lovins LH. Factor four-doubling wealth, halving 22 resource use. London: Earthscan, 1997.
Nations, 1988 . The International Bill of Human Rights. New York: United

Abel Wolman Lecture (summarised by Iqbal Sram, NHS Executive North West, Warrington) WATER, LIFE AND JUSTICE

An insight into the clear connection between public health and meaningful human rights has been eloquently expressed in the 1998 Abel Wolman lecture, entitled "Water, Life and Justice", delivered at the National Academy of Sciences, Washington DC by the South African Member of Parliament, Professor Kader Asmal.

As the Minister for Water Affairs and Forestry, with a background in Human Rights Law, and having spent many years as an exile in Ireland at Trinity College, Dublin, Professor Kader is well placed to bring to the attention of an international audience the essential relation between human rights, natural resources and the health of the public through his South African experience.

In the era of the New World Order and Globalisation, the key challenges are the attainment of sustainable peace within and between nations. This desirable sustainability fundamentally depends on the equitable and fair access to the natural, technological and intellectual resources of the globe. However, equitable access must be underpinned by responsible and efficient resource use. The current global distribution of economic power, wealth and resources between nations and within nations has resulted in there being the "haves" and the "have nots"

In an attempt to produce a fairer and more equitable society, the South African government has produced a National Water Bill that asserts the public interest in water distribution and use. The Bill not only enshrines the public's right of access to navigable waterways, but also reasserts the individual citizen's right to safe and clean water, while Acess to water

A most important limiting factors to the creation of a just society in South Afrecersual access to water the current technical solutions to the mane resulted in the current inequities. For the poor, in particular women, the lack of adequate and easily accessible water supplies restricts the quality of family life as well as the economic development of local communities.

The techniques and policies used to manage water resources illuminate the related wider process of economic and social development These instruments also help shape the structure of international relations. There is a Zulu term, "Ubuntu", which means that you can only become a full person through your social interaction with others in the community. This is one of the best illustrations of the traditional African values that underpin the government's policy which aims to promote equity in access to water supply.

The South African situation poses considerable challenges to policy makers committed to the principles of equity in this context. In South Africa the access to water supply is related to the ownership of the most fertile land. The link between fertility of land and proximity of the water supply means that most of the available water supply is attached to the land owned by the minority white community, leaving the vast majority of the people in South Africa on land with low fertility and inadequate water supplies.

Market inspired solutions, based as they are on the price mechanism, are ill equipped to resolve this unsatisfactory and historically created situation. Hence the government's action plan via the Bill to implement a comprehensive and integrated approach to the management of water resources in the public interest is the appropriate response. This action plan contains within it policy proposals, roles for institutions and practices to support the attainment of the overall aim of the equitable and easy access to the nation's water supplies for the population. The action plan resonates with a well known but ancient Zulu phrase, "isandla siyagezana", which means one hand washes the other. The phrase amply illustrates that notions of cooperation and interdependence tend to permeate most if not all cultures.

The full lecture can be obtained from Professor Kader Asmal MP at the following address:

Professor Kader Asmal MP, Minister of Water Affairs and Forestry, Private Bag X313, Pretoria 0001, South Africa. 